\title{
Differential mortality rates in major and subthreshold depression: meta-analysis of studies that measured both
}

\author{
Pim Cuijpers, Nicole Vogelzangs, Jos Twisk, Annet Kleiboer, Juan Li and Brenda W. Penninx
}

\section{Background}

Although the association between depression and excess mortality has been well established, it is not clear whether this is greater in major depression than in subthreshold depression.

\section{Aims}

To compare excess mortality in major depression with that in subthreshold depression.

\section{Method}

We searched bibliographic databases and included prospective studies in which both major and subthreshold depression were examined at baseline and mortality was measured at follow-up.

\section{Results}

A total of 22 studies were included. People with major depression had a somewhat increased chance of dying earlier than people with subthreshold depression but this difference was not significant, although there was a trend (relative risk $1.13,95 \% \mathrm{Cl} 0.98-1.30, P=0.1$ ). The population attributable fraction was $7 \%$ for major depression and an additional $7 \%$ for subthreshold depression.

\section{Conclusions}

Although excess mortality may be somewhat higher in major than in subthreshold depression, the difference is small and the overall impact on excess mortality is comparable.

\section{Declaration of interest}

None.
After more than 150 years of research on the subject, it is now well established that mental disorders are associated with excess mortality. ${ }^{1-3}$ The association between depression and excess mortality has been shown in several hundreds of studies in many different populations, including community samples, heart disease patients, cancer patients, stroke patients and patients with diabetes. ${ }^{4-15}$ It is not yet clear, however, whether the increased mortality rates only exist in major depressive disorder, or also extend to subthreshold depression. Many studies examining excess mortality in depression have used a cut-off score on self-report instruments to indicate the presence of depressive symptoms. It is possible that the increased mortality rate in these samples can be fully attributed to the people with major depression. However, it is also possible that the increased mortality rate exists not only in major depression but also in subthreshold depression. Many studies have shown that subthreshold depression in itself is a clinically relevant condition, with decreased levels of health-related quality of life, increased use of health services and increased economic costs when compared with healthy controls. ${ }^{16-19}$ When people with subthreshold depression are compared with those who have a major depressive disorder, however, it is typically found that on an individual level health-related quality of life, health service use and economic costs are more affected in major depression than in subthreshold depression. From this perspective it would be expected that if there is an association between excess mortality and subthreshold depression it would be less strong than in major depression. Because the prevalence of subthreshold depression is higher than that of major depression, earlier research has found that the impact of subthreshold depression on (for example) economic costs is comparable with the costs of major depression. ${ }^{20}$ The same may be true for the impact of subthreshold and major depression on mortality. In order to examine these questions, a meta-analysis of studies in which participants with major depression as well as those with subthreshold depression were included would be most informative. These studies allow comparison of major and subthreshold depression directly with each other and establish whether excess mortality is higher in major depression than in subthreshold depression. We decided to conduct such a meta-analysis.

\section{Method}

Studies were traced by several methods. First, we conducted comprehensive literature searches (up to November 2011) in three bibliographic databases (PubMed, PsycINFO and EMBASE). In these searches we combined words indicating depression (such as major depression, mood disorder, depression, depressive), mortality (such as death, survival), and prospective design (such as incidence, follow-up studies, longitudinal studies, prospective studies). Both text and keywords were used. We also checked the references of included studies, as well as the references of earlier meta-analyses examining the association between depression and mortality. ${ }^{5-13,21-27}$ We retrieved the full text of papers reporting studies that possibly met inclusion criteria. Full-text papers were examined by two independent raters for possible inclusion. Disagreements were solved by discussion and if necessary a third rater was involved.

Studies were included if they examined two groups: participants with a major depressive disorder (established with a diagnostic interview; either major depression alone or combined with dysthymia); and participants with subthreshold depression (established through a self-report depression measure or a diagnostic interview) but no major depressive disorder. Studies also had to have a prospective design and report all-cause mortality at follow-up, for both groups. We included studies in any target group (community samples and specific patient groups), as well as case-control studies. Studies were excluded when insufficient data were presented to calculate the relative risk of dying in the group with major depression compared with subthreshold depression (main analysis). We also excluded studies based on trials examining the effects of an intervention, studies in children and adolescents, and studies in languages other than English, German and Dutch. 


\section{Data extraction and quality assessment}

We rated the number of deaths in the group with major depression, the group with subthreshold depression and the non-depressed control group. When these data were not reported in the papers, we contacted the first authors of the studies. If no answer was received within 2 weeks, a reminder was sent. Additional data on six studies were received from the researchers (see Acknowledgements). For the subgroup (moderator) analyses we rated several characteristics of the included studies: target population (community sample, heart disease patients, other patient group); percentage of women in the target population ( $<40 \%, 40-60 \%,>60 \%)$; definition of subthreshold depression (scoring above a cut-off on self-report measure $v$. fulfilling diagnostic DSM-IV criteria for minor depression); follow-up period ( $<2$ years, $2-5$ years, $>5$ years); and country where the study was conducted (USA, Europe, other).

In order to assess the validity of the studies we used a quality rating scale that was based on the instrument developed by Hayden et al. ${ }^{28}$ We adapted the specific items for use with the studies in this field, but retained five of the six basic areas of potential bias that are assessed with this instrument: study participation (the study sample represents the population of interest on key characteristics), study attrition, adequate outcome measurement, adequate measurement of confounding variables and adequate statistical analysis. The sixth area of potential bias (the prognostic factor of interest is adequately measured) was not used because an adequate measure of depression (major and subthreshold) was an inclusion criterion for this study. The rating instrument is presented online in Appendix DS1, and the ratings for the included studies are presented in online Table DS1.

\section{Meta-analyses}

For each study we calculated the relative risk of dying during the study in the group with major depression compared with the group with subthreshold depression. This was the main comparison for each study. However, all studies also included a non-depressed control group. We also calculated the relative risks of dying for the groups with major depression and subthreshold depression compared with the non-depressed group. Because we did not collect all studies that compared major depression or subthreshold depression with non-depressed controls, these comparisons should be considered with caution; we conducted these analyses only to confirm that earlier associations between depression and excess mortality were also found in our sample of studies.

Because all studies reported the exact number of deaths in the depressed and non-depressed groups, unadjusted relative risks (RRs) were calculated for all studies. None of the studies reported RRs (comparing major depression with subthreshold depression) that were adjusted for demographics or other variables. Therefore, all analyses were conducted with unadjusted RRs. To calculate pooled RRs we used the computer program Comprehensive Meta-analysis for Windows version 2.2.021. As we expected considerable heterogeneity among the studies, we decided to calculate the pooled RR using a random effects model. Because the actual heterogeneity we found was low, we additionally conducted the meta-analyses according to the fixed effects model.

In order to examine heterogeneity we calculated the $I^{2}$ statistic, which is an indicator of heterogeneity in percentages. A value of $0 \%$ indicates no observed heterogeneity, and larger values show increasing heterogeneity ( $25 \%$ low, $50 \%$ moderate, $75 \%$ high). ${ }^{29}$ We calculated $95 \%$ confidence intervals around $I^{2}, 30$ using the non-central $\chi^{2}$-based approach within the 'heterogi' module for Stata/MP11.0 for Mac. ${ }^{31}$ To test for significant heterogeneity we also calculated the $Q$ statistic, but only report whether this was significant or not. Subgroup analyses were conducted according to the mixed effect model, in which studies within subgroups are pooled with the random effects model, whereas tests for significant differences between subgroups are conducted with the fixed effects model. Because the actual heterogeneity we found was low in most analyses, we also conducted the subgroup analyses using the fixed effects model to examine both within-group and between-group differences.

Publication bias was tested by inspecting the funnel plot and by Duval \& Tweedie's trim and fill procedure, ${ }^{32}$ which yields an estimate of the effect size after the publication bias has been taken into account (as implemented in Comprehensive Meta-analysis for Windows version 2.2.021). We also conducted Egger's test of the intercept to quantify the bias captured by the funnel plot and tested whether it was significant.

We expected that the mortality rate in subthreshold depression would be lower than in major depression, but that the prevalence of subthreshold depression would be higher. This would make it possible that the overall impact of subthreshold depression on mortality rates is comparable to or higher than the impact of major depression. In order to examine this we calculated the population attributable fraction (PAF) of major depression and subthreshold depression. The PAF indicates the potential reduction in mortality if the adverse effect of depression were to be completely blocked. ${ }^{33,34}$ We based the overall PAF of subthreshold depression and major depression on the pooled prevalence rates and the pooled mortality rates. Although the PAF assumes that the excess mortality is fully caused by depression, which is not the case (see Discussion), it does give an indication of the relevance of subthreshold and major depression from a public health perspective.

\section{Results}

Having examined 6694 abstracts (5919 after removal of duplicates), we retrieved 975 full-text papers for further consideration. We excluded 953 of the retrieved papers (Fig. 1). Twenty-two studies

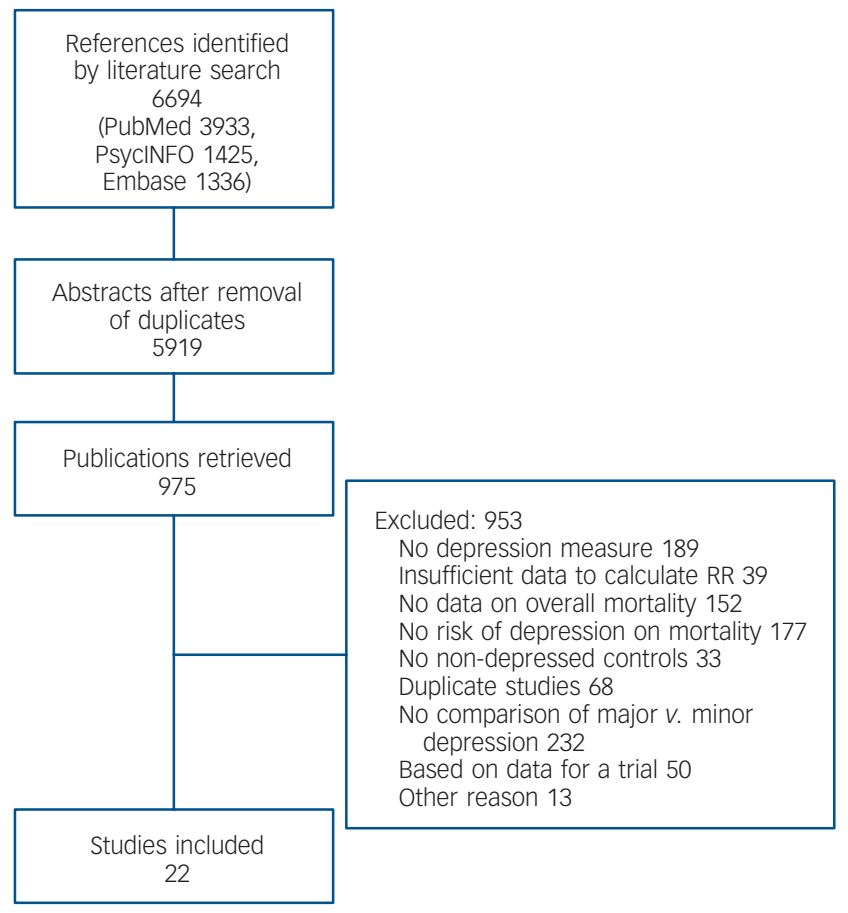

Fig. 1 Flowchart of inclusion of studies: RR, relative risk. 
examined both major and subthreshold depression and were included in this meta-analysis. ${ }^{35-56}$

\section{Characteristics of included studies}

Selected characteristics of the 22 included studies are presented in online Table DS2. These studies included 18705 participants (1147 had a diagnosed depressive disorder, 3238 had subthreshold depression and 14320 had no depression), of whom 2881 died during follow-up. Seven studies were conducted among community samples, six among heart disease patients and nine in other patient groups (two on stroke patients, two on cancer patients, two on medical in-patients with diverse diagnoses, one on dementia patients, one on nursing home residents and one on patients with their first diabetic foot ulcer). Seven studies included less than $40 \%$ women, six $40-60 \%$ women and seven more than $60 \%$ women. Thirteen studies used a cut-off score on a self-report questionnaire to define subthreshold depression, whereas the other nine studies used diagnostic criteria for minor depression (such as Research Diagnostic Criteria or the criteria given in DSM-IV). Nine studies had a follow-up period of less than 2 years, eight studies had a follow-up period of 2-5 years and in four studies the follow-up was more than 5 years. Nine studies were conducted in the USA, seven in Europe and six in other countries. Nine studies scored positive on at least four of the five quality criteria, whereas the remaining 13 studies scored lower (online Table DS1).

\section{Mortality in major $\boldsymbol{v}$. subthreshold depression}

We examined the relative risk of dying in patients with major depression compared with those with subthreshold depression
(Table 1, Fig. 2). The risk was 1.13 (95\% CI 0.98-1.30, random effects model), indicating a somewhat increased risk of dying for major depression compared with subthreshold depression. This RR was not significant, although there was a trend $(P=0.10$ in the random effects model and $P=0.06$ in the fixed effects model) indicating an increased mortality risk in major depression. Heterogeneity was low and not significant $(P>0.1)$. The RR after adjustment for publication bias was exactly the same as the unadjusted RR (one trimmed study), and Egger's test of the intercept was not significant $(P>0.1)$. We found no significant difference between any of the subgroups with the random effects model or with the fixed effects model (Table 1). Because the differences between the models were small, we report only the results according to the random effects model, which is the optimal model.

\section{Comparisons with participants without depression}

We compared the mortality rates in major and subthreshold depression respectively with the rate in participants without depression. As indicated, we did this only to verify that the two forms of depression were associated with a higher mortality rate compared with participants without depression in our sample of studies, as suggested in earlier meta-analyses. We found that the relative risk of dying in major depression compared with participants without depression was 1.58 (95\% CI $1.31-1.89$, $P<0.001)$ in the random effects model, with moderate to high heterogeneity $\left(I^{2}=56 \%, P<0.01\right)$. The RR of dying in subthreshold depression compared with participants without depression was smaller than in major depressive disorders $(\mathrm{RR}=1.33$, 95\% CI 1.11-1.61, random effects model $)$ with high

\begin{tabular}{|c|c|c|c|c|c|}
\hline & $n$ & $\mathrm{RR}$ & $95 \% \mathrm{Cl}$ & $I^{2 \mathrm{~b}}$ & $95 \% \mathrm{Cl}$ \\
\hline Major v. subthreshold depression & 22 & 1.13 & $0.98-1.30$ & 13.32 & $0-48$ \\
\hline \multicolumn{6}{|l|}{ Subgroup analyses ${ }^{\mathrm{c}}$} \\
\hline \multicolumn{6}{|l|}{ Population } \\
\hline Community & 7 & 1.04 & $0.85-1.27$ & 0 & $0-71$ \\
\hline Heart disease & 6 & 1.05 & $0.66-1.67$ & 24.19 & $0-68$ \\
\hline Other patient group & 9 & 1.24 & $0.95-1.64$ & 41.23 & $0-73$ \\
\hline \multicolumn{6}{|l|}{ Subthreshold depression } \\
\hline Self-reported & 13 & 1.15 & $0.97-1.36$ & 8.12 & $0-46$ \\
\hline Diagnostic criteria & 9 & 1.07 & $0.78-1.45$ & 27.72 & $0-66$ \\
\hline \multicolumn{6}{|l|}{ Country } \\
\hline USA & 9 & 1.12 & $0.82-1.54$ & 41.62 & $0-73$ \\
\hline Europe & 7 & 1.01 & $0.79-1.30$ & 0 & $0-71$ \\
\hline Other & 6 & 1.18 & $0.98-1.43$ & 0 & $0-75$ \\
\hline \multicolumn{6}{|l|}{ Follow-up ${ }^{d}$} \\
\hline$<2$ years & 9 & 1.08 & $0.68-1.72$ & 47.79 & $0-76$ \\
\hline $2-5$ years & 8 & 1.11 & $0.94-1.31$ & 0 & $0-68$ \\
\hline$>5$ years & 4 & 1.06 & $0.84-1.35$ & 0 & $0-85$ \\
\hline \multicolumn{6}{|l|}{ Quality score } \\
\hline 4 or higher & 9 & 1.19 & $0.95-1.48$ & 36.25 & $0-71$ \\
\hline Lower than 4 & 13 & 1.06 & $0.88-1.29$ & 0 & $0-57$ \\
\hline \multicolumn{6}{|l|}{ Proportion of women ${ }^{\mathrm{e}}$} \\
\hline$<40 \%$ & 7 & 1.16 & $0.70-1.91$ & 23.93 & $0-66$ \\
\hline $40-60 \%$ & 6 & 1.01 & $0.81-1.28$ & 0 & $0-75$ \\
\hline$>60 \%$ & 7 & 1.19 & $0.96-1.48$ & 24.96 & $0-67$ \\
\hline \multicolumn{6}{|l|}{ Other comparisons } \\
\hline Major depression v. non-depressed & 22 & 1.58 & $1.31-1.89 * * *$ & $52.87 * *$ & $52-80$ \\
\hline Subthreshold depression $v$. non-depressed & 22 & 1.33 & $1.11-1.61$ ** & $69.13^{* * *}$ & $23-71$ \\
\hline \multicolumn{6}{|c|}{$\begin{array}{l}\text { a. All reported results are based on the random effects model. } \\
\text { b. The } P \text { values in this column indicate whether the } Q \text { statistic is significant. } \\
\text { C. None of the differences between the effect sizes in the subgroups was significant. } \\
\text { d. The study of von Ammon Cavanaugh } e t \text { a } l^{55} \text { did not report the exact follow-up period and was excluded from these analyses. } \\
\text { e. Two studies in which the percentage of female participants was not reported were excluded (Jorm et } a l, 1991,{ }^{42} \text { von Ammon Cavanaugh et al, } 2001^{55} \text { ). } \\
\star * P<0.01, * * * P<0.001 \text {. }\end{array}$} \\
\hline
\end{tabular}




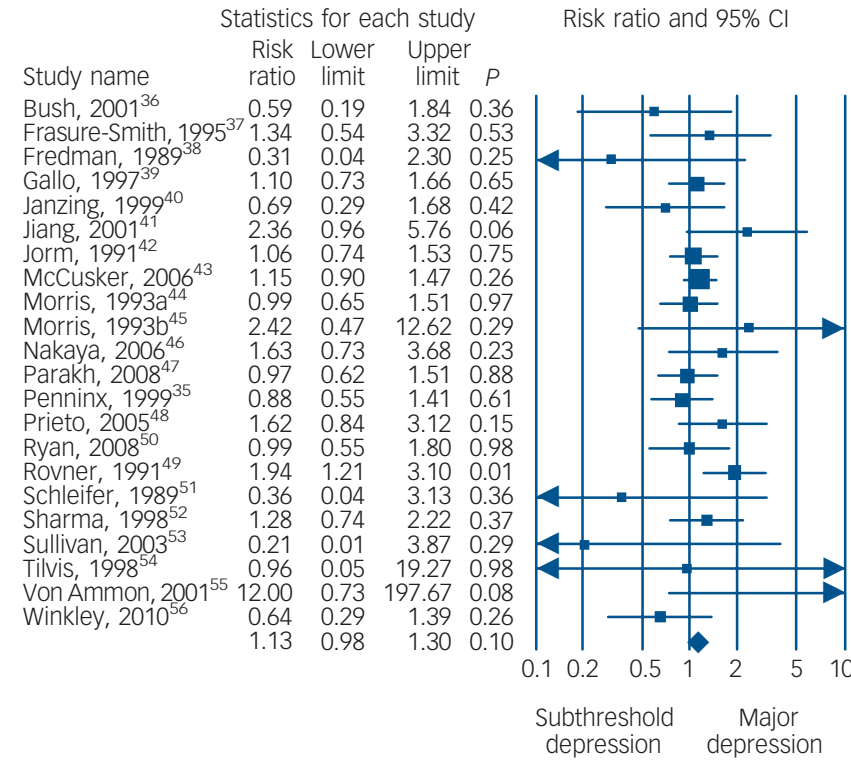

Fig. 2 Studies directly comparing mortality rates in major and subthreshold depression: relative risks.

heterogeneity $\left(I^{2}=69 \%, P<0.001\right)$. The results of the fixed effects models were comparable (not presented in Table 1).

\section{Population attributable fraction}

The pooled prevalence rate of subthreshold depression was 0.17 (95\% CI 0.10-0.28, random effects model) which was somewhat higher than the pooled prevalence rate of major depressive disorder $(0.10,95 \%$ CI $0.06-0.16)$; the case-control study by Sharma et al was excluded from the latter prevalence estimate. ${ }^{52}$ To examine the overall impact of major depression and subthreshold depression on mortality in the population, we calculated the population attributable fraction of major depression and subthreshold depression. We found that the PAF of major and subthreshold depression together was 0.137 , indicating that the overall mortality would be reduced by $14 \%$ if the adverse effects of depression could be blocked completely. The PAF of subthreshold depression was 0.065 and that of major depression was 0.072 , indicating that the impact on mortality of the two types of depression are comparable.

\section{Discussion}

Direct comparisons between the mortality rates in major depression and subthreshold depression showed that there was a trend $(P<0.1)$ indicating that the mortality rate in people with major depression may be somewhat higher than in people with subthreshold depression $(\mathrm{RR}=1.13)$. We also found that both major depression $(\mathrm{RR}=1.58)$ and subthreshold depression $(\mathrm{RR}=1.33)$ were associated with a significantly increased risk of mortality compared with non-depressed samples $(P<0.001)$. This is in agreement with the findings of most earlier meta-analyses. Together, these findings suggest that both major and subthreshold depression are associated with increased mortality rates, but that there is not much difference between the rates in the two types of depression. This is further strengthened by the findings on the PAF. We found that the PAFs of both major and subthreshold depression are about 0.07 . This indicates that mortality would decline by $7 \%$ if we could block the adverse effects of major depression, and by another $7 \%$ if we could block the adverse effects of subthreshold depression. Although the risk of dying is somewhat higher in major depression the prevalence of major depression is lower, resulting in comparable PAFs. This is in agreement with other research showing that the impact of subthreshold depression on quality of life, service use and economic costs is lower than in major depression on an individual level, ${ }^{16,20}$ but that it is comparable with major depression on the population level because of the higher prevalence.

The relative risks we found for major and subthreshold depression compared with non-depressed controls were somewhat lower than in most other meta-analyses. ${ }^{4,7,25}$ Although higher RR was not confirmed in all meta-analyses, ${ }^{27}$ this could indicate that our sample of studies was not representative of all studies examining the association between depression and mortality. However, because there is no clear consensus between the different meta-analyses it is not possible to verify this, and further research is needed to confirm it.

\section{Limitations}

This study has several limitations. First, although the number of studies was relatively large, the number of participants with major or subthreshold depression was not. Because we were interested in the differential mortality rates in these two conditions, we may not have had sufficient statistical power to detect smaller differences between the two groups. On the other hand, the $95 \%$ confidence interval of the RR ranged from 0.98 to 1.30 , which indicates that it is unlikely that the ultimate risk is larger than 1.30. This would still only be an association of limited strength. A second limitation is that the quality of the studies was not optimal in all cases. This may have influenced our results, although we did not find significant differences between higher- and lower-quality studies. Third, we were only capable of examining unadjusted associations between major $v$. subthreshold depression and mortality. There is much evidence showing that a large part of the association between depression and excess mortality can be explained by lifestyle, behavioural and illness- related factors, although it is unclear whether this is also relevant for the comparison between major and subthreshold depression. Nonetheless, it is possible that had we adjusted for these factors the association between major $v$. subthreshold depression and mortality might have changed, although the direction of such a change cannot be predicted. More research is certainly warranted to explore this issue further. Fourth, in the included studies depression was measured only once (at baseline). It is highly possible that participants with subthreshold depression met criteria for major depression at some time in their past or during the follow-up period, that participants without depression had had a depressive disorder at some point in their life, and that participants with major depression did not meet diagnostic criteria 1 month earlier. This might well have distorted our outcomes. Because of these limitations the results of our studies have to be considered with caution.

\section{Implications}

It is not yet clear what the exact causes are of the increased mortality rates in people with depressive disorders. There is evidence that part of the excess mortality can be explained by an increased risk of suicide in people with depression, ${ }^{57}$ by hazardous health behaviours such as physical inactivity, ${ }^{58}$ increased smoking rates, ${ }^{59}$ more alcohol consumption and unhealthy eating patterns, ${ }^{35,60,61}$ and by biological dysregulation, including hyperactivity of the hypothalamic-pituitary-adrenal axis, neuroimmune dysregulation and sympathoadrenergic dysregulation. ${ }^{62-64}$ However, it remains unclear for most of these 
explanatory mechanisms what the causal direction is. It is possible that depressive disorders lead to hazardous health behaviours and biological dysregulation, but it is also possible that these factors have a role in the development of depressive disorders, or that both are explained by a third, underlying factor.

This study has made it clear that the association between depression and excess mortality is not limited to major depression. Apparently, the mechanisms through which depression is associated with mortality are also working in less severe forms of depression. It makes sense that unhealthy lifestyles as well as biological pathways are responsible for the excess mortality in major as well as subthreshold depression. These findings suggest that depression should not be seen as a distinct category with unique characteristics, but rather as a continuum ranging from no depression on the one hand to severe depression on the other, with subthreshold depression in between. ${ }^{65,66}$ Another implication of our findings is that the effects of subthreshold depression might be less severe than those of major depression in individual cases, but because of its high prevalence the impact on public health is comparable with that of major depression. This could be seen as an indication that subthreshold depression is a clinically relevant condition that does require treatment. Although there is no evidence that antidepressants and benzodiazepines are effective for this condition, ${ }^{67}$ brief psychological treatments have been shown to be effective. ${ }^{68}$

\section{Future research}

We found little evidence that excess mortality is much higher in major depression than in subthreshold disorder, and in terms of population impact the two are comparable. More research on the exact mechanisms through which depression is associated with excess mortality might help in further understanding and possibly reducing this excess mortality.

Pim Cuijpers, PhD, Department of Clinical Psychology, Vrije Universiteit (VU) University Amsterdam, and EMGO Institute for Health and Care Research, Amsterdam; Nicole Vogelzangs, PhD, EMGO Institute for Health and Care Research, Amsterdam, and Department of Psychiatry, VU University Medica Centre, Amsterdam; Jos Twisk, PhD, EMGO Institute for Health and Care Research, Amsterdam; Annet Kleiboer, PhD, Department of Clinical Psychology, VU University Amsterdam, and EMGO Institute for Health and Care Research, Amsterdam, The Netherlands; Juan Li, PhD, Institute of Psychology, Chinese Academy of Sciences, Beijing, China; Brenda w. Penninx, PhD, EMGO Institute for Health and Care Research, Amsterdam, and Department of Psychiatry, VU University Medical Centre Amsterdam, The Netherlands

Correspondence: Professor Pim Cuijpers, Department of Clinical Psychology, VU University Amsterdam, Van der Boechorststraat 1, 1081 BT Amsterdam, The Netherlands. Email: p.cuijpers@vu.nl

First received 19 Mar 2012, final revision 28 Jun 2012, accepted 17 Aug 2012

\section{Acknowledgements}

We thank the following researchers for their kind collaboration and for providing additional data on their studies: Dr Nancy Frasure-Smith, Dr Joan Ryan, Dr Kirsty Winkley, Dr Reijo Tilvis, Dr Jane McCusker, Dr Kapil Parakh and Dr Naoki Nakaya.

\section{References}

1 Brown S. Excess mortality of schizophrenia. A meta-analysis. Br J Psychiatry 1997; 171: $502-8$

2 Odegard O. Excess mortality of the insane. Acta Psychiatr Scand 1952; 27: 353-67.

3 Alstrom CH. Mortality in Mental Hospitals with Especial Regard to Tuberculosis. Munksgaard, 1942.

4 Cuijpers $P$, Smit F. Excess mortality in depression: a meta-analysis of community studies. J Affect Disord 2002; 72: 227-36.
5 Saz P, Dewey ME. Depression, depressive symptoms and mortality in persons aged 65 and over living in the community: a systematic review of the literature. Int J Geriatr Psychiatry 2001; 16: 622-30.

6 Wulsin LR, Vaillant GE, Wells VE. A systematic review of the mortality of depression. Psychosom Med 1999; 61: 6-17.

7 Barth J, Schumacher M, Herrman-Lingen C. Depression as a risk factor for mortality in patients with coronary heart disease: a meta-analysis. Psychosom Med 2004; 66: 802-13.

8 Nicholson A, Kuper $\mathrm{H}$, Hemingway $\mathrm{H}$. Depression as an aetiologic and prognostic factor in coronary heart disease: a meta-analysis of 6362 events among 146538 participants in 54 observational studies. Eur Heart J 2006; 27 : 2763-74.

9 Sorensen C, Friis-Hasche E, Haghfelt T, Bech P. Postmyocardial infarction mortality in relation to depression: a systematic critical review. Psychother Psychosom 2005; 74: 69-80.

10 Van Melle JP, de Jonge P, Spijkerman TA, Tijssen JGP, Ormel J, van Veldhuisen DJ, et al. Prognostic association of depression following myocardial infarction with mortality and cardiovascular events: a meta-analysis. Psychosom Med 2004; 66: 814-22.

11 Chida Y, Hamer M, Wardle J, Steptoe A. Do stress-related psychosocial factors contribute to cancer incidence and survival? Nat Clin Pract 2008; 5: $466-75$.

12 Pinquart M, Duberstein PR. Depression and cancer mortality: a meta-analysis. Psychol Med 2010; 40: 1797-810.

13 Pan A, Sun Q, Okereke Ol, Rexrode KM, Hu FB. Depression and risk of stroke morbidity and mortality: a meta-analysis and systematic review. JAMA 2011; 306: 1241-9.

14 Bruce DG, Davis WA, Starkstein SE, Davis TME. A prospective study of depression and mortality in patients with type 2 diabetes: the Fremantle Diabetes Study. Diabetologia 2005; 48: 2532-9.

15 Lin EHB, Heckbert SR, Rutter CM, Katon WJ, Ciechanowski P, Ludman EJ, et al. Depression and increased mortality in diabetes: unexpected causes of death. Ann Fam Med 2009; 7: 414-21.

16 Cuijpers P, Smit F. Subthreshold depression as a risk indicator for majo depressive disorder: a systematic review of prospective studies. Acta Psychiatr Scand 2004; 109: 325-31.

17 Rucci P, Gherardi S, Tansella M, Piccinelli M, Berardi D, Bisoffi G, et al Subthreshold psychiatric disorders in primary care: prevalence and associated characteristics. J Affect Disord 2003; 76: 171-81.

18 Chachamovich E, Fleck M, Laidlaw K, Power M. Impact of major depression and subsyndromal symptoms on quality of life and attitudes toward aging in an international sample of older adults. Gerontologist 2008; 48: 593-602.

19 Goldney RD, Fisher L, Dal Grande E, Taylor AW. Subsyndromal depression: prevalence, use of health services and quality of life in an Australian population. Soc Psychiatry Psychiatr Epidemiol 2004; 39: 293-8.

20 Cuijpers $P$, Smit F, Oostenbrink J, de Graaf R, ten Have M, Beekman A Economic costs of minor depression: a population-based study. Acta Psychiatr Scand 2007; 115: 229-36.

21 Cole MG. Does depression in older medical inpatients predict mortality? A systematic review. Gen Hosp Psychiatry 2007; 29: 425-30.

22 Hoodin F, Weber S. A systematic review of psychosocial factors affecting survival after bone marrow transplantation. Psychosomatics 2003; 44 $181-95$

23 Lawrence D, Kisely S, Pais J. The epidemiology of excess mortality in people with mental illness. Can J Psychiatry 2010; 55: 752-60.

24 Rutledge T, Reis VA, Linke SE, Greenberg BH, Mills PJ. Depression in heart failure; a meta-analytic review of prevalence, intervention effects, and associations with clinical outcomes. J Am Coll Cardiol 2006; 48: 1527-37.

25 Satin JR, Linden W, Phillips MJ. Depression as a predictor of disease progression and mortality in cancer patients; a meta-analysis. Cancer 2009: 115: 5349-61.

26 Schulz R, Drayer RA, Rollman BL. Depression as a risk factor for non-suicide mortality in the elderly. Biol Psychiatry 2002; 52: 205-25.

27 Van den Akker Ml, Schuurman AG, Ensinck KTJL, Buntinx F. Depression as a risk factor for total mortality in the community: a meta-analysis. Arch Public Health 2003; 61: 313-32.

28 Hayden JA, Cote $\mathrm{P}$, Bombardier C. Evaluation of the quality of prognosis studies in systematic reviews. Ann Intern Med 2006; 144: 427-37.

29 Higgins JP, Thompson SG, Deeks JJ, Altman DG. Measuring inconsistency in meta-analyses. BMJ 2003; 327: 557-60.

30 Ioannidis JPA, Patsopoulos NA, Evangelou E. Uncertainty in heterogeneity estimates in meta-analyses. BMJ 2007; 335: 914-6. 
31 Orsini N, Higgins J, Bottai M, Buchan I. Heterogi: Stata module to quantify heterogeneity in a meta-analysis. 2005 (http://econpapers.repec.org/ software/bocbocode/S449201.htm).

32 Duval S, Tweedie R. Trim and fill: a simple funnel-plot-based method of testing and adjusting for publication bias in meta-analysis. Biometrics 2000 56: 455-63.

33 Smit F, Ederveen A, Cuijpers P, Deeg D, Beekman A. Opportunities for cost-effective prevention of late-life depression: an epidemiological approach. Arch Gen Psychiatry 2006; 63: 290-6.

34 Rothman KJ, Greenland S. Modern Epidemiology, 2nd ed. Lippincott-Raven, 1998.

35 Penninx BW, Geerlings SW, Deeg DJ, Van Eijk JT, Van Tilburg W, Beekman AT. Minor and major depression and the risk of death in older persons. Arch Gen Psychiatry 1999; 56: 889-95.

36 Bush DE, Ziegelstein RC, Tayback M, Richter D, Stevens S, Zahalsky H. Even minimal symptoms of depression increase mortality risk after acute myocardial infarction. Am J Cardiol 2001; 88: 337-41.

37 Frasure-Smith N, Lesperance F, Talajic M. Depression and 18-month prognosis after myocardial infarction. Circulation 1995; 91: 999-1005.

38 Fredman L, Schoenbach VJ, Kaplan BH, Blazer DG, James SA, Kleinbaum DG, et al. The association between depressive symptoms and mortality among older participants in the Epidemiologic Catchment Area - Piedmont Health Survey. J Gerontol 1989; 44: S149-56.

39 Gallo JJ, Rabins PV, Lyketsos CG, Tien AY, Anthony JC. Depression without sadness: functional outcomes of nondysphoric depression in later life. J Am Geriatr Soc 1997; 45: 570-8.

40 Janzing JG, Bouwens JM, Teunisse RJ, Van't Hof MA, Zitman FG. The relationship between depression and mortality in elderly subjects with less severe dementia. Psychol Med 1999; 29: 979-83.

41 Jiang W, Alexander J, Christopher E, Kuchibhatla M, Gaulden LH, Cuffe MS, et al. Relationship of depression to increased risk of mortality and rehospitalization in patients with congestive heart failure. Arch Intern Med 2001; 161: 1849-56.

42 Jorm AF, Henderson AS, Kay DWK. Mortality in relation to dementia, depression and social integration in an elderly community sample. Int J Geriatr Psychiatry 1991; 6: 5-11.

43 McCusker J, Cole M, Ciampi A, Latimer E, Windholz S, Belzile E. Does depression in older medical inpatients predict mortality? J Gerontol Biol A Sci Med Sci 2006; 61: 975-81.

44 Morris PL, Robinson RG, Andrzejewski P, Samuels J, Price TR. Association of depression with 10-year poststroke mortality. Am J Psychiatry 1993; 150 124-9.

45 Morris PL, Robinson RG, Samuels J. Depression, introversion and mortality following stroke. Aust N Z J Psychiatry 1993; 27: 443-9.

46 Nakaya N, Saito-Nakaya K, Akizuki N, Yoshikawa E, Kobayakawa M, Fujimori M, et al. Depression and survival in patients with non-small cell lung cancer after curative resection: a preliminary study. Cancer Sci 2006; 97 : 199-205.

47 Parakh K, Thombs BD. Effect of depression on late (8 years) mortality after myocardial infarction. Am J Cardiol 2008; 101: 602-6.

48 Prieto JM, Atala J, Blanch E, Rovina M, Cicera E, Espinal A, et al. Role of depression as a predictor of mortality among cancer patients after stem-cell transplantation. J Clin Oncol 2005; 23: 6063-71.

49 Rovner BW, German PS, Brant L, Clark R, Burton L, Folstein MF. Depression and mortality in nursing homes. JAMA 1991; 265: 993-6.
50 Ryan J, Carriere I, Ritchie K, Stewart R, Toulemonde G, Dartigues JF, et al. Late-life depression and mortality: influence of gender and antidepressant use. Br J Psychiatry 2008; 192: 12-8.

51 Schleifer SJ, Macari-Hanson MM, Coyle DA, Slater WR, Kahn M, Gorlin R, et al. The nature and course of depression following myocardial infarction. Arch Intern Med 1989; 149: 1785-9.

52 Sharma VK, Copeland JR, Dewey ME, Lowe D, Davidson I. Outcome of the depressed elderly living in the community in Liverpool: a 5-year follow-up. Psychol Med 1998; 28: 1329-37.

53 Sullivan M, LaCroix A, Spertus J, Hecht J, Russo J. Depression predicts revascularization procedures for 5 years after coronary angiography. Psychosom Med 2003; 65: 229-36.

54 Tilvis RS, Pitkala K, Nevantaus H. Prognosis of depression in old age. Arch Gerontol Geriatr 1998; 26 (suppl 6): 491-8.

55 Von Ammon Cavanaugh S, Furlanetto LM, Creech SD, Powell LH. Medical illness, past depression, and present depression: a predictive triad for in-hospital mortality. Am J Psychiatry 2001; 158: 43-8.

56 Winkley K, Stahl D, Chalder T, Edmonds ME, Ismail K. Risk factors associated with adverse outcomes in a population-based prospective cohort study of people with their first diabetic foot ulcer. J Diabetes Complications 2007; 21: 341-9.

57 Botswick JM, Pankratz VS. Affective disorders and suicide risk: a reexamination. Am J Psychiatry 2000; 157: 1925-32.

58 Whooley MA, de Jonge P, Vittinghoff E, Otte C, Moos R, Carney RM, et al. Depressive symptoms, health behaviors, and risk of cardiovascular events in patients with coronary heart disease. JAMA 2008; 300: 2379-88.

59 Dierker LC, Avenevoli S, Stolar M, Merikangas KR. Smoking and depression: an examination of mechanisms of comorbidity. Am J Psychiatry 2002; 159: 947-53.

60 Holahan CJ, Moos RH, Holahan CK, Cronkite RC, Randall PK. Drinking to cope and alcohol use and abuse in unipolar depression: a 10-year model. J Abnorm Psychol 2003; 112: 159-65.

61 Luppino FS, de Wit LM, Bouvy PF, Stijnen T, Cuijpers P, Penninx BWJH, et al. Body mass index (BMI) and depression: meta-analysis of longitudinal studies. Arch Gen Psychiatry 2009; 67: 220-9.

62 Cesari M, Penninx BW, Newman A, Kritchevsky SB, Nicklas BJ, Sutton-Tyrrell $K$, et al. Inflammatory markers and onset of cardiovascular events: results from the Health ABC study. Circulation 2003; 108: 2317-22.

63 Pariante $\mathrm{CM}$. Depression, stress and the adrenal axis. J Neuroendocrinol 2003; 15: 811-2.

64 Cuijpers P, Schoevers RA. Increased mortality in depressive disorders: a review. Curr Psychiatr Rep 2004; 6: 430-7.

65 Solomon A, Haaga DA, Arnow BA. Is clinical depression distinct from subthreshold depressive symptoms? A review of the continuity issue in depression research. J Nerv Ment Dis 2001; 189: 498-506.

66 Cuijpers P, De Graaf R, Van Dorsselaer S. Minor depression: risk profiles, functional disability, health care use and risk of developing major depression. J Affect Disord 2004; 79: 71-9.

67 Barbui C, Cipriani A, Patel V, Ayuso-Mateos JL, van Ommeren M. Efficacy of antidepressants and benzodiazepines in minor depression: systematic review and meta-analysis. Br J Psychiatry 2011; 198: 11-6.

68 Cuijpers $P$, van Straten A, Smit F. Psychological treatments of subthreshold depression: a meta-analytic review. Acta Psychiatr Scand 2007; 115: 434-41. 